\title{
Eluting antibiotic bone graft substitutes for the treatment of osteomyelitis in long bones. A review: evidence for their use?
}

This article was published in the following Dove Press journal:

Orthopedic Research and Reviews

16 September 2014

Number of times this article has been viewed

\section{Carsten W Schlickewei Sinef Yarar Johannes M Rueger}

Department of Trauma, Hand and Reconstructive Surgery, University Medical Center Hamburg-Eppendorf, Hamburg, Germany
Correspondence: Carsten W Schlickewei Department of Trauma, Hand and Reconstructive Surgery, University Medical Center Hamburg-Eppendorf, Martinistrasse 52, Hamburg 20246,

Germany

Email c.schlickewei@uke.de
Abstract: Despite continuous advances in surgical procedures and antibiotic therapies, osteomyelitis still remains one of the most devastating complications in trauma and orthopedic surgery. Treatment of osteomyelitis represents a severe and challenging problem, even if the treatment of acute cases with systemic antibiotics has good success rates. Chronic cases need a consequent resection of dead or infected bone in addition to an improved systemic and local antibiotic therapy. The gold standard therapy is the implantation of polymethylmethacrylate as spacer and local antibiotic carrier. Besides other drawbacks, nonbiodegradable polymethylmethacrylate implants need to be removed. This led to an ongoing search for a biodegradable antibiotic bone graft substitute for the treatment of osteomyelitis to avoid secondary removal. The number of clinically available products grows, but still, the available number of peer-reviewed clinical trials to prove their efficiency is limited. This review gives an overview of the current available literature.

Keywords: osteomyelitis, bone infection, eluting antibiotics, bone graft substitutes, antibiotic bone graft

\section{Introduction}

Infections remain a serious problem in trauma and orthopedic surgery. Especially, the therapy of osteomyelitis represents an ambitious and challenging problem. Healthy adult bone is extremely resistant to infection. ${ }^{1}$ This is the reason why osteomyelitis often occurs in patients with predisposing factors such as diabetes, immunosuppression, or peripheral arterial disease. While in adults, osteomyelitis often occurs after traumatic infections or in combination with predisposing factors; in children, osteomyelitis follows in most cases after a hematogenous spread of the infection and without any predisposing, underlying illnesses.

Prolonged bone infections are characterized as chronic osteomyelitis. Reaching a chronic status, the infection often requires a radical surgical resection, and this leads in many cases to a large loss of bone and soft tissue. Inadequate resection of infected tissue increases the reinfection rate.

Beside the surgical treatment with resection and debridement of the infected bone, an early antibiogram-specific therapy for osteomyelitis is necessary. ${ }^{2}$

A side effect of chronic bone infections is the impairment of the local vascularity. This causes serious problems in ensuring effective local antibiotic doses after parental or oral drug substitution. The local implantation of an antimicrobial agent represents an easy method to reach higher local antibiotic concentrations. ${ }^{3}$ Polymethylmethacrylate (PMMA) has been successfully used as a local antibiotic carrier for the treatment of osteomyelitis over the last decades. But due to the fact that PMMA has to be removed 
during the treatment process, can be responsible for thermal necrosis, and might lead to antibiotic resistance formation, researchers are looking for a replacement.

The use of a biodegradable bone graft substitute as an antibiotic carrier would avoid surgical removal of the implant, reduce systemic side effects, and shorten the period of treatment. ${ }^{3}$

\section{Literature search}

A systematic literature search was carried out on the PubMed database, examining the entire available literature. The following search strings were used: "osteomyelitis bone graft substitutes" and "osteomyelitis antibiotic bone graft;" 285 papers were detected. The results were supplemented by a hand search. Only articles addressing orthopedic trauma and reconstruction surgery were reviewed. After screening the abstracts, a full-text evaluation was carried out. The bibliography of the collected papers was searched to find as many related publications as possible. Only English language publications were included in the review process. At the end, 84 papers could be analyzed and integrated into the review process.

\section{Pathology of osteomyelitis}

Osteomyelitis represents an inflammatory and progressive bacterial infection of bone. In the modern world, it was first described in 1852 by the French surgeon Edouard Chassaignac in a case of a 2 -year-old child. ${ }^{4}$ But already in the 17 th century BC, osteomyelitis was specified in the Egyptian Edwin Smith Papyrus - probably the oldest trauma text in human history. ${ }^{5}$

Cases of osteomyelitis of long bones occur most often after accidents, surgeries, or after combat traumas. ${ }^{6,7}$ In adults, hematogenous bacteremia most frequently leads to cases of vertebral osteomyelitis.

The tibia is the bone with the most documented infections in the literature. Today Staphylococcus aureus is the most commonly attested bacteria for inflammatory infection of bone, followed by Pseudomonas and Enterobacteriaceae. ${ }^{3,8}$ Patients present with swelling, erythema, and pain over the infected area, accompanied by chills and fever. ${ }^{9}$ Chronic osteomyelitis can additionally lead to prolonged or failed wound healing and requires a detailed medical, antibiotic, and surgical history. For diagnosis, blood cultures, needle or open bone biopsies are necessary.

Osteomyelitis can be classified using two different major systems: the Cierny-Mader classification and the Waldvogel classification system. ${ }^{10,11}$ The original staging system, the Waldvogel classification, presented in 1970, is an etiologic system based on the pathogenesis of the infection, differentiating between three categories: hematogenous, contiguous focus, and osteomyelitis associated with vascular insufficiency. ${ }^{11}$

The Cierny-Mader classification, reported in 2003, categorizes osteomyelitis according to the anatomy of the infected bone and to the physiology of the host. This classification allows the development of comprehensive treatment guidelines and prognoses for each stage. ${ }^{10}$

Different factors are responsible for the loss of bone during an osteomyelitis infection. In addition to an initial trauma, the surgical resection of the infected bone evokes bone defects that make bone grafting or the use of bone graft substitutes necessary. Furthermore, osteolytic cytokines and osteonecrosis factors released by the bacteria damage the bone. ${ }^{12}$ The progressive infection of the bone and the surrounding tissue results in an intense inflammatory response, causing local thrombosis and weakening of the blood supply. This provokes an undersupply of oxygen and shortage of nutrition of the bone and the surrounding tissue, resulting in bone infarcts with abscess and sequestrum formation. ${ }^{8}$ Furthermore, the incoming amount of the antibiotic is limited and ends in a poor antibiotic concentration, especially in the infected bone itself.

In these poor blood supported areas, bacteria can multiply, almost without meeting any resistance. Given time, the bacterial microorganisms are able to form biofilms that add additional protection against antibodies and the antibiotic therapy. ${ }^{13}$ Biofilm formation results in a need for ten to 100 times increased antibiotic concentrations to fight bacteria. ${ }^{14,15}$

All these factors together and in different combinations lead to the formation of necrotic bone and sequestrum. For adequate treatment of chronic osteomyelitis in combination with biofilm appearance, a complete implant removal and a radical surgical debridement is necessary. To ensure mechanical stability of the defect after removal of the implant, an overlapping external fixation is necessary. ${ }^{16}$ The implantation of a new local implant into the infection is not useful until the infection is adequately eradicated.

\section{History}

The idea to treat osteomyelitis with antibiotic impregnated bone grafts was first described by Prigge in 1946. He combined autologous bone graft with local application of penicillin to fill bone defects after resection of dead bone after chronic osteomyelitis in 61 male patients. ${ }^{17}$ One year 
later, De Grood was the first to use cancellous bone as an antibiotic carrier. ${ }^{18} \mathrm{He}$ treated two cases of osteomyelitis by filling bony defects after surgical resection of infected bone with penicillin-impregnated cancellous bone graft. Although the results were quite promising, the procedure was discontinued after Hogeman ${ }^{19}$ in 1949 and Buchman and Blair ${ }^{20}$ in 1951 presented unsuccessful treatments. It took more than 30 years until the idea to use a cancellous bone graft as an antibiotic delivery vehicle was rediscovered by McLaren and Miniachi in $1986 .^{21}$

\section{Antibiotic therapy}

The systemic antibiotic therapy of osteomyelitis occurs intravenously and orally. It requires an antibiotic agent matching the antibiogram of the bacteria. The advantage of a systemic antibiotic therapy is the possibility to deliver the antibiotics to areas that cannot be reached with a topical therapy. Drawbacks to a systematic antibiotic treatment are the potential for drug-related toxicity with organ failure, gastrointestinal side effects, allergic reactions, and the possible lack of reaching therapeutic concentrations in the infected area. ${ }^{22-24}$ Because of the poor penetration of bone, a systemic antibiotic therapy is unable to eradicate the bacteria in a chronic state.

Beside this, any antibiotic treatment of chronic osteomyelitis will fail if there is no sufficient surgery with considerable debridement, no soft tissue coverage is secured, and the local blood supply is not optimized. ${ }^{13,25}$ The high risk of a continuous infection explains the need for a systemic postoperative antibiotic therapy. According to the literature, a postoperative systemic antibiotic therapy is recommended for 4 to 6 weeks and is founded on a period of 4 weeks for revascularization of bone grafts after resection and transplantation. ${ }^{26,27}$

Nevertheless, the efficiency of a systemic antibiotic therapy for chronic osteomyelitis is highly improbable. The avascularity and the porous structure of newly implanted bone grafts prevent a therapeutic antibiotic level in the bone defect. ${ }^{28}$ Further problems occur with the increasing number of highly resistant bacteria such as methicillin resistant S. aureus (MRSA). ${ }^{29}$

Multiple animal trials have proven that a local antibiotic therapy using different delivery systems represents a useful and safe treatment option for osteomyelitis. ${ }^{30-35}$ Effective treatment of chronic osteomyelitis with tobramycin-impregnated bone graft substitutes in humans could be shown by various authors. ${ }^{27,36,37}$ Different studies promote a bone graft substitute impregnated with the combination of vancomycin and tobramycin. ${ }^{29,38}$ Vancomycin antagonizes most Gram-positive bacteria. Additionally, vancomycin represents the agent of choice against MRSA. ${ }^{38}$ Tobramycin is effective against many Gram-negative and Gram-positive bacteria. ${ }^{29}$ Vancomycin and tobramycin-impregnated bone grafts have successfully been used as bone graft substitutes in the bony defects after osteomyelitis in humans. ${ }^{39,40}$ Nevertheless, there is only poor or almost no data regarding the actual antibiotic concentration levels and the appropriate dosage regimen. ${ }^{41} \mathrm{Up}$ to the present day, the ideal antibiotic and dosage for a local therapy of osteomyelitis has not been found.

\section{PMMA}

In the last decades, the use of PMMA has been regarded as the local antibiotic delivery system to prevent higher loads of antibiotic concentration in bony defects. ${ }^{42,43}$ Klemm used gentamicin-PMMA beads as local antibiotic therapy after surgical debridement in chronic osteomyelitis, with a success quotient of $91.4 \%$ of 128 cases. $^{44}$

Representing the gold standard, PMMA has the advantages of sufficient elution characteristics and excellent structural support properties. ${ }^{14}$ According to the literature, PMMA is impregnated with vancomycin, ${ }^{45}$ tobramycin, ${ }^{45,46}$ daptomycin, ${ }^{47,48}$ and gentamycin. ${ }^{49,50}$ However, the use of PMMA is accompanied by a number of disadvantages. During the preparation and mixing of PMMA, high temperatures $\left(100^{\circ} \mathrm{C}\right)$ occur, which can lead to denaturation of the integrated antibiotic and to thermal necrosis at the implant site. Ultimately, the PMMA implant has to be removed since it is not biodegradable, and the implant itself can create bacterial resistance if the antibiotic concentration drops over the course of time, and the PMMA implant acts as a foreign body. ${ }^{51-53}$

\section{The ideal bone graft substitute}

Regarding the literature, an ideal bone graft should demonstrate three properties: osteoinduction, osteoconduction, and osteogenesis. In addition, a bone graft must be able to encase and integrate into the host to avoid graft-versus-host reactions. ${ }^{54}$ Autologous bone grafts still represent the gold standard in bone grafting containing bone matrix, growth factors, osteoblasts, and osteoprogenitor cells. ${ }^{3,55}$ Regardless of these factors, the amount of autologous bone grafting is limited, and the donor-site morbidity is high.

Owing to the growing requirement for bone grafts, the US orthopedic bone graft substitute market is increasing. ${ }^{56}$ Due to this increasing use of bone graft substitutes and the rising number of multiresistant organisms, an antibacterial factor should be added as a fourth property to an ideal bone graft. 
The materials used as bone graft substitutes differ in their properties of osteoinduction, osteoconduction, osteogenesis, and stability. Osteoinductive materials have bioactive properties that stimulate the differentiation of undifferentiated and pluripotent cells into a bone-forming cell line. An osteoconductive bone graft provides a surface that promotes the ingrowth of bone and blood vessels. Osteogenesis describes the process of new bone formation originating from transplanted living cells. Bone graft substitutes themselves do not have osteogenetic properties in contrast to autologous bone. Only in composites can osteogenetic properties be added for example using bone marrow aspirates.

In addition to the four basic properties, an ideal bone graft substitute should be biocompatible, bioresorbable, structurally similar to bone, easy to use, and cost-effective.

\section{Treatment of osteomyelitis: the current state of the art}

Today, the gold standard therapy of chronic osteomyelitis is performed in a two-step treatment, beginning in the first step with a systematic antibiotic therapy, surgical debridement, and local antibiotic treatment with PMMA, followed by a second step of removing the PMMA implant and surgical reconstruction of the resulting bony defect. This leads to delayed recovery in the patient. To shorten the treatment time, reduce the number of operations, minimize cost, and eliminate the various drawbacks of PMMA, biodegradable bone graft substitutes as possible antibiotic carrier came increasingly into focus. ${ }^{57}$

\section{Bone graft substitutes}

The idea to use bone graft substitutes proposed to combine its possible use as local antibiotic delivery system to eradicate infection, with its regeneration possibilities to treat bony defects and support new bone formation after debridement of an infected bone. The biodegradable properties eliminate the need to remove the implant at a later time point and reduce the risk of bacterial resistance over the course of time. ${ }^{41}$ Also, the degradation of a biodegradable bone graft substitute ensures to elute the complete antibiotic load of the implant. Different biodegradable bone graft substitutes have been investigated (Table 1).

\section{Calcium sulfate}

Calcium sulfate has been used as an antibiotic carrier in previous studies, ${ }^{36,58}$ thereby verifying its clinical effectiveness and its reliability as an antibiotic carrier. Initial problems with degradation of the antibiotic during production or the sterilization of the calcium sulfate were solved by Gitelis and Brebach in 2002. ${ }^{27}$ The structure of calcium sulfate determines its mechanical properties. The tensile stability is a little bit lower while its compressive stability is greater than the stability of cancellous bone..$^{59}$

Calcium sulfate as bone graft substitute has an osteoconductive property. In different studies, calcium sulfate could show good resorption rates and good biocompatibility. ${ }^{60-62}$ Nevertheless, the dissolution of calcium sulfate leads to an acidic microenvironment, responsible for local inflammatory processes at the site of implantation. ${ }^{61,62}$

Already, in 2002, McKee et al ${ }^{36}$ treated 25 patients (15 males and ten females) with a culture-positive, long bone infection using tobramycin impregnated calcium sulfate. They showed an effective eradication rate of $92 \%$ after posttraumatic osteomyelitis. The isolated bony infections, without earlier operation, healed in $100 \%$ of the cases, and 14 of the 16 patients with previous therapy achieved union. Nine patients required an extra surgery using autologous bone graft.

A report by Turner et $\mathrm{al}^{63}$ was published showing sufficient local antibiotic concentrations of tobramycin over a period of 14 to 28 days after implantation of calcium sulfate pellets loaded with $10 \%$ tobramycin in a contained medullary defect in the proximal humeri of canines.

Also, Thomas et $\mathrm{al}^{57}$, in 2005 , presented positive results for the use of tobramycin-impregnated calcium sulfate to treat stable unicortical defects in the proximal tibial metaphysis infected with $S$. aureus.

The increasing prevalence of antibiotic-resistant bacterial infections represents a growing and threatening problem in clinical practice. To counteract this, Richelsoph et $\mathrm{al}^{64}$ and Webb et $\mathrm{a}^{65}$ used daptomycin as a new powerful lipopeptide antibiotic to impregnate calcium sulfate. Webb documented the ability to elute daptomycin to inhibit bacterial growth of S. aureus and Staphylococcus epidermidis up to 28 days. ${ }^{65}$

\section{Synthetic polymers}

Synthetic polymers such as polylactide acid (PLA), polyglycolide, polylactide-co-glycolide (PLGA), polycaprolactone, polyhydroxybutyrate-co-hydroxyvalerate, cross-linked polydimethylsiloxane, and polyhydroxyalkanoates have been tested and investigated as local antibiotic drug delivery implants. ${ }^{14,41,66-68}$ All these materials have the properties to work as antibiotic-impregnated graft delivery systems, with further evaluation and development. ${ }^{67}$

In 1997, Mader et al ${ }^{69}$ evaluated the elution of clindamycin, tobramycin, and vancomycin out of PLA, PLGA, 
Table I Literature review addressing sufficient local antibiotic concentrations after implantation of eluting antibiotic bone graft substitutes for the treatment of osteomyelitis

\begin{tabular}{|c|c|c|c|c|}
\hline Study & $\begin{array}{l}\text { Year of } \\
\text { publication }\end{array}$ & Bone graft & Antibiotic(s) & $\begin{array}{l}\text { Sufficient } \\
\text { concentrations }\end{array}$ \\
\hline \multirow[t]{10}{*}{ Mader et $\mathrm{a}^{69}$} & 1997 & Polylactide acid (PLA) & Clindamycin & For 30 days \\
\hline & & & Tobramycin & \\
\hline & & & Vancomycin & \\
\hline & & Polylactide-co-glycolide (PLGA) & Clindamycin & For 30 days \\
\hline & & & Tobramycin & \\
\hline & & & Vancomycin & \\
\hline & & Composite PLA + PLGA & Clindamycin & For 30 days \\
\hline & & & Tobramycin & \\
\hline & & & Vancomycin & \\
\hline & & PMMA & Vancomycin & 12 days \\
\hline Liu et $\mathrm{al}^{70}$ & 2002 & PLGA & Vancomycin & 55 days \\
\hline Turner et $\mathrm{al}^{63}$ & 2005 & Calcium sulfate & Tobramycin & $14-28$ days \\
\hline \multirow[t]{2}{*}{ Rauschmann et $a^{84}$} & 2005 & Composite hydroxyapatite & Vancomycin & 10 days \\
\hline & & and calcium sulfate & Gentamycin & \\
\hline Webb et $a^{165}$ & 2008 & Calcium sulfate & Daptomycin & Up to 28 days \\
\hline \multirow[t]{2}{*}{ Ueng et $\mathrm{al}^{71}$} & 2011 & Composite PLGA + collagen & Vancomycin & 56 days \\
\hline & & impregnated with MSC & & \\
\hline Wang et $\mathrm{a}^{85}$ & 2011 & Composite calcium sulfate and BMP-2 & Vancomycin & 21 days \\
\hline \multirow[t]{2}{*}{ Chang et a ${ }^{82}$} & 2013 & Tissue engineered construct: DBM & Vancomycin & 28 days \\
\hline & & scaffold + BMSC & & \\
\hline \multirow[t]{2}{*}{ Maier et $\mathrm{a}^{89}$} & 2013 & Beta tricalcium phosphates & Vancomycin & 4-6 days \\
\hline & & & Gentamycin & \\
\hline
\end{tabular}

Abbreviations: BMSC, bone marrow stromal cells; DBM, demineralized bone matrix; MSC, mesenchymal stem cells; PMMA, polymethylmethacrylate.

a composite of PLA and PLGA, and PMMA. PLA, PLGA, and the composite released concentrations of clindamycin, tobramycin, and vancomycin above the breakpoint sensitivity for a period of at least 30 days. PMMA was able to effectively elute vancomycin for 12 days only.

Liu et al, ${ }^{70}$ in 2002, investigated PLGA beads impregnated with vancomycin in a rabbit model. They could measure minimal vancomycin over a 55 -day period. ${ }^{70}$

Another research group developed a composite of PLGA copolymer (PLGA) as an antibiotic carrier for vancomycin in combination with collagen loaded with mesenchymal stem cells as a biodegradable bone graft substitute for treatment of osteomyelitis in an animal model. ${ }^{71}$ PLGA is an organic substance based on lactic acids. As carrier, it is an atoxic material, eliciting only a minimal inflammatory response during its biodegradation, ${ }^{71,72}$ while collagen is known as a good and low immunogenic bone graft. ${ }^{73}$ Using a rabbit model, Ueng et $\mathrm{al}^{71}$ detected a minimal vancomycin concentration in the bony defect over 56 days and good bone regeneration.

Huang et $\mathrm{al}^{74}$ were able to develop biodegradable, ultrafine, double-layered fibers through a coaxial electrospinning process using polycaprolactone and gentamycin. The implant is very interesting, while degradation of the implant and elution of the drugs can be controlled by the rate of hydrophilicity. Nonetheless, the degradation of the different polymers varies greatly, making a comparison very difficult. The literature describes at least four different degradation types for polymers: chemical, mechanical, photo, and thermal degradation. ${ }^{75}$

\section{Bioactive glass: a noneluting antibiotic bone graft substitute}

Bioactive glasses (BAGs) are used as biodegradable osteoconductive bone graft substitutes. BAGs are hard and solid materials that are based on silicon compounds. By varying their structural composition, their abilities can vary from resorbable to nonresorbable. ${ }^{59,76}$ They are not used as antibiotic carriers but known to have antibacterial and angiogenesis promoting properties. ${ }^{77}$ They bond to bone and muscles. ${ }^{78}$ BAG-S53P4 has been evaluated as an antibiotic treatment option in different studies. In eleven cases of osteomyelitis, healing was achieved after surgery and implantation of BAGS53P4 in nine of eleven patients, while one patient had an infection because of a hematoma and one retained a superficial wound infection due to vascular problems of a muscle flap. ${ }^{77}$ Drago et al ${ }^{79}$ treated 27 patients with osteomyelitis using BAG-S53P4. ${ }^{79}$ They published a success rate of $88.9 \%$ (24 of 27 patients) after a follow-up average of 18 months. One patient had to undergo plastic surgery while two patients showed a recurrent infection - one of the two, due to an infection with MRSA, the other had a polymicrobial infection. 
McAndrew et al,,$^{80}$ in 2013, presented a short study successfully treating chronic osteomyelitis with BonAlive ${ }^{\circledR}$ and intravenous and oral antibiotic therapy in two males and one female after a mean follow-up of 17.3 months.

\section{Tissue engineering}

Using tissue engineering, Xing et al ${ }^{81}$ created a biodegradable composite of vancomycin alginate beads and fibrin gel scaffolds to treat chronic osteomyelitis in a rabbit model, promoting positive results. Chang et a ${ }^{82}$ confirmed these results in a goat model, reporting a minimum inhibitory concentration (MIC) of vancomycin against $S$. aureus in a bone defect for at least 28 days.

\section{Composites}

Shirtliff et a ${ }^{83}$ used calcium hydroxyapatite impregnated with vancomycin in a rabbit osteomyelitis model after intramedullary injection of MRSA. After radical reaction of the infected bone, he could prove eradication for MRSA in the calcium hydroxyapatite group in $81.8 \%$ compared to the PMMA vancomycin group with a $70 \%$ clearance rate.

Rauschmann et a $1^{84}$ used PerOssal ${ }^{\circledR}$ as a composite of nanoparticulate hydroxyapatite and calcium sulfate to reduce the known cytotoxic effects of calcium sulfate. In a comparison of calcium sulfate to the nanoparticulate hydroxyapatite calcium sulfate composite, gentamicin equally eluted out of both carriers within 10 days, while the release of vancomycin initially was higher in the composite, and after 5 days, was higher in the calcium sulfate. Whereas the composite of nanoparticulate hydroxyapatite and calcium sulfate showed good antibiotic release of the impregnated antibiotics and good resorption and biocompatibility, calcium sulfate produced cytotoxic reactions in two of four tests.

Wang et a ${ }^{85}$ showed good antibiotic elution over 21 days and significantly augmented new bone formation in a rabbit model using a composite of calcium sulfate loaded with recombinant human BMP-2 and vancomycin.

In 2011, Karr et a ${ }^{86}$ presented an in vitro study using a calcium sulfate and hydroxyapatite composite disc (Cerament ${ }^{\mathrm{TM}}$ ) as an antibiotic carrier for different antibiotics against $S$. aureus and Pseudomonas aeruginosa. They reported inhibition zones against $S$. aureus of $33 \%$ to $222 \%$ and against $P$. aeruginosa of $93 \%$ to $200 \%$ greater than the minimum of inhibition breakpoints defined by the Clinical and Laboratory Standards Institute. ${ }^{87}$ In the same year, $\mathrm{Karr}^{88}$ released an article reporting the successful treatment of diabetic foot osteomyelitis in a clinical off-label use of Cerament ${ }^{\mathrm{TM}}$ impregnated with vancomycin.
Maier et al ${ }^{89}$ compared the beta tricalcium phosphates Cerasorb $^{\circledR}$ and Cerasorb ${ }^{\circledR} \mathrm{M}$ as antibiotic carrier systems impregnated with gentamycin and vancomycin. They reported elution rates for both materials over the MIC of S. aureus. While Cerasorb ${ }^{\circledR}$ had a higher elution rate and an MIC rate for 6 days, Cerasorb ${ }^{\circledR}$ M showed lower rates and a MIC for 4 days only.

\section{Discussion}

Different materials have been evaluated as antibiotic bone graft substitutes. While not matching the group of eluting antibiotic bone graft substitutes and with limited clinical data, bioactive glass seems to be a good alternative in the treatment of chronic osteomyelitis.

To the present day, the potential use of synthetic polymers and tissue engineered implants as antibiotic delivery systems for the treatment of chronic osteomyelitis has been investigated in several studies. They show promising results, but still, no clinical product has been successfully launched, and the available clinical data is insufficient.

Even though calcium sulfate and hydroxyapatite as bone graft substitutes in humans have been investigated for a long time, as antibiotic carriers, the review of the literature shows limited clinical data. The presented results for infection control in short-term studies are good, and compared to the other bone graft substitutes investigated as antibiotic carrier systems, calcium sulfate and hydroxyapatite have the most reliable data, representing a promising alternative to the current treatment.

The different materials reviewed show promising results in the treatment of chronic osteomyelitis but overall, the clinical data are poor. As published by McLaren, ${ }^{67}$ in 2004, the various study designs, different animal models, unequal antibiotic concentrations, and varying antibiotic agents give no possibility to compare the different outcomes. The results of in vitro and in vivo studies do not correlate. Surgical procedures, implant preparations, elution fluids, and antibiotic concentrations differ widely from each other. The knowledge about release rates, not only in humans but also in connection with the implantation site, have to be more thoroughly investigated and understood since locally delivered antibiotics still have the potential for systemic toxicity. ${ }^{90,91}$ Although there are differences in elution for different antibiotics, all seem to have adequate elution for the treatment of osteomyelitis $;{ }^{92}$ however, the length of time that the antibiotic drug level remains over the MIC varies. Since it is not possible to create an osteomyelitis model equal to a human case, the results of the different materials 
have to be rated individually, and if promising, clinical trials have to be performed to be able to compare the materials against each other.

As Kurien et $\mathrm{al}^{3}$ already published, the literature not only shows limited evidence for antibiotic bone graft substitutes but it is also limited for most of the regular available bone graft substitutes as well.

Until further trials have been completed, and especially more clinical data has been collected, the use of biodegradable bone graft substitutes as antibiotic carriers remains off label. Therefore, it is important to differentiate between the US and the European Union. While in Europe, different Conformitée Européenne (CE) marked antibiotic bone graft substitutes for the treatment of osteomyelitis exist, the Food and Drug Administration in the US has not cleared or approved any antibiotic bone graft substitute to our knowledge.

\section{Disclosure}

The authors report no conflicts of interest in this work.

\section{References}

1. Andriole VT, Nagel DA, Southwick WO. A paradigm for human chronic osteomyelitis. J Bone Joint Surg Am. 1973;55(7):1511-1515.

2. Concia E, Prandini N, Massari L, et al. Osteomyelitis: clinical update for practical guidelines. Nucl Med Commun. 2006;27(8):645-660.

3. Kurien T, Pearson RG, Scammell BE. Bone graft substitutes currently available in orthopaedic practice: the evidence for their use. Bone Joint J. 2013;95-B(5):583-597.

4. Chassaignac E. De l'osteo-myelite. Bull Mem Soc Chir. 1852: 431-436.

5. Breasted JH. The Edwin Smith Surgical papyrus (facsimile and hieroglyphic transliteration with translation and commentary, in two volumes). Chicago: The University of Chicago Press; 1930.

6. Mabry RL, Holcomb JB, Baker AM, et al. United States Army Rangers in Somalia: an analysis of combat casualties on an urban battlefield. J Trauma. 2000;49(3):515-528; discussion 528-529.

7. Trampuz A, Zimmerli W. Diagnosis and treatment of infections associated with fracture-fixation devices. Injury. 2006;37(Suppl 2): S59-S66.

8. Ciampolini J, Harding KG. Pathophysiology of chronic bacterial osteomyelitis. Why do antibiotics fail so often? Postgrad Med J. 2000;76(898):479-483.

9. Kumar V, Abul AK, Nelson F, Richard MN. Robbins Basic Pathology. 8th ed. Philadelphia, PA: Saunders Elsevier; 2007:810-811.

10. Cierny G 3rd, Mader JT, Penninck JJ. A clinical staging system for adult osteomyelitis. Clin Orthop Relat Res. 2003;414:7-24.

11. Waldvogel FA, Medoff G, Swartz MN. Osteomyelitis: a review of clinical features, therapeutic considerations and unusual aspects. N Engl J Med. 1970;282(4):198-206.

12. Gasparini G, Cerciello S, Vasso M, Fabbriciani C. Pathological findings of septic loosening. In: Meani E, Romanò C, Crosby L, Hofmann G, editors. Infection and Local Treatment in Orthopedic Surgery. Berlin: Springer-Verlag; 2007:39-48.

13. Dinh P, Hutchinson BK, Zalavras C, Stevanovic MV. Reconstruction of osteomyelitis defects. Semin Plast Surg. 2009;23(2):108-118.

14. Gogia JS, Meehan JP, Di Cesare PE, Jamali AA. Local antibiotic therapy in osteomyelitis. Semin Plast Surg. 2009;23(2):100-107.

15. Nelson CL. The current status of material used for depot delivery of drugs. Clin Orthop Relat Res. 2004;427:72-78.
16. Patzakis MJ, Zalavras CG. Chronic posttraumatic osteomyelitis and infected nonunion of the tibia: current management concepts. $J \mathrm{Am}$ Acad Orthop Surg. 2005;13(6):417-427.

17. Prigge EK. The treatment of chronic osteomyelitis by the use of muscle transplant or iliac graft. J Bone Joint Surg Am. 1946;28:576-593.

18. De Grood DM. Het plomeren van restholten na osteomyelitis met "bonechips". Ned Tijdschr Geneeskd. 1947;91.III.32:2192-2196. Dutch.

19. Hogeman KE. Treatment of infected bone defects with cancellous bone-chip grafts. Acta Chir Scand. 1949;98(3-6):576-590, 4 pl.

20. Buchman J, Blair JE. The surgical management of chronic osteomyelitis by saucerization, primary closure, and antibiotic control; preliminary report on use of aureomycin. J Bone Joint Surg Am. 1951;33(A:1): 107-118; passim.

21. McLaren AC, Miniachi A. In vivo study to determine the efficacy of cancellous bone graft as a delivery vehicle for antibiotics. Proceeding of the 12th Annual Meeting of the Society of Biomaterials; May 28-June 1, 1986; Minneapolis, Minnesota, USA.

22. Antoci V, Adams CS, Hickok NJ, Shapiro IM, Parvizi J. Antibiotics for local delivery systems cause skeletal cell toxicity in vitro. Clin Orthop Relat Res. 2007;462:200-206.

23. Edin ML, Miclau T, Lester GE, Lindsey RW, Dahners LE. Effect of cefazolin and vancomycin on osteoblasts in vitro. Clin Orthop Relat Res. 1996;333:245-251.

24. Stiefeld SM, Graziani AL, MacGregor RR, Esterhai JL Jr. Toxicities of antimicrobial agents used tot treat osteomyelitis. Orthop Clin North Am. 1991;22(3):439-465.

25. Mader JT, Cripps MW, Calhoun JH. Adult posttraumatic osteomyelitis of the tibia. Clin Orthop Relat Res. 1999;360:14-21.

26. Chang W, Colangeli M, Colangeli S, Di Bella C, Gozzi E, Donati D. Adult osteomyelitis: debridement versus debridement plus Osteoset T pellets. Acta Orthop Belg. 2007;73(2):238-243.

27. Gitelis S, Brebach GT. The treatment of chronic osteomyelitis with a biodegradable antibiotic-impregnated implant. J Orthop Surg (Hong Kong). 2002;10(1):53-60.

28. Day RE, Megson S, Wood D. Iontophoresis as a means of delivering antibiotics into allograft bone. J Bone Joint Surg Br. 2005;87(11): $1568-1574$.

29. Winkler H, Janata O, Berger C, Wein W, Georgopoulos A. In vitro release of vancomycin and tobramycin from impregnated human and bovine bone grafts. J Antimicrob Chemother. 2000;46(3): 423-428.

30. Aimin C, Chunlin H, Juliang B, Tinyin Z, Zhichao D. Antibiotic loaded chitosan bar. An in vitro, in vivo study of a possible treatment for osteomyelitis. Clin Orthop Relat Res. 1999;366:239-247.

31. Beardmore AA, Brooks DE, Wenke JC, Thomas DB. Effectiveness of local antibiotic delivery with an osteoinductive and osteoconductive bone-graft substitute. J Bone Joint Surg Am. 2005;87(1):107-112.

32. Calhoun JH, Mader JT. Treatment of osteomyelitis with a biodegradable antibiotic implant. Clin Orthop Relat Res. 1997;341:206-214.

33. Humphrey JS, Mehta S, Seaber AV, Vail TP. Pharmacokinetics of a degradable drug delivery system in bone. Clin Orthop Relat Res. 1998;349:218-224.

34. Mader JT, Stevens CM, Stevens JH, Ruble R, Lathrop JT, Calhoun JH. Treatment of experimental osteoyelitis with a fibrin sealant antibiotic implant. Clin Orthop Relat Res. 2002;403:58-72.

35. Solberg BD, Gutow AP, Baumgaertner MR. Efficacy of gentamycinimpregnated resorbable hydroxyapatite cement in treating osteomyelitis in a rat model. J Orthop Trauma. 1999;13(2):102-106.

36. McKee MD, Wild LM, Schemitsch EH, Waddell JP. The use of an antibiotic-impregnated, osteoconductive, bioabsorbable bone substitute in the treatment of infected long bone defects: early results of a prospective trial. J Orthop Trauma. 2002;16(9):622-627.

37. McKee MD, Li-Bland EA, Wild LM, Schemitsch EH. A prospective, randomized clinical trial comparing an antibioticimpregnated bioabsorbable bone substitute with standard antibiotic-impregnated cement beads in the treatment of chronic osteomyelitis and infected nonunion. J Orthop Trauma. 2010;24(8):483-490. 
38. Cui X, Zhao C, Gu Y, et al. A novel injectable borate bioactive glass cement for local delivery of vancomycin to cure osteomyelitis and regenerate bone. J Mater Sci Mater Med. 2014;25(3):733-745.

39. Lack W, Bösch P, Arbes H. Long term results with the use of homologous spongiosa grafting in connection with fibrin sealant in the treatment of chronic osteomyelitis. In: Schlag G, Redl H, editors. Fibrin Sealant in Operative Medicine: Traumatology and Orthopaedics. Vol 7. Berlin: Springer-Verlag; 1986:183-188.

40. McLaren AC. Antibiotic impregnated bone graft: post-op levels of vancomycin and tobramycin. J Orthop Trauma. 1989;3:171.

41. Hanssen AD. Local antibiotic delivery vehicles in the treatment of musculoskeletal infection. Clin Orthop Relat Res. 2005;437:91-96.

42. Joseph TN, Chen AL, Di Cesare PE. Use of antibiotic-impregnated cement in total joint arthroplasty. J Am Acad Orthop Surg. 2003;11(1): 38-47.

43. Ostermann PA, Seligson D, Henry SL. Local antibiotic therapy for severe open fractures. A review of 1085 consecutive cases. J Bone Joint Surg Br. 1995;77(1):93-97.

44. Klemm K. [Gentamicin-PMMA-beads in treating bone and soft tissue infections (author transl)]. Zentralbl Chir. 1979;104(14):934-942.

45. Scott DM, Rotschafer JC, Behrens F. Use of vancomycin and tobramycin polymethylmethacrylate impregnated beads in the management of chronic osteomyelitis. Drug Intell Clin Pharm. 1988;22(6):480-483.

46. Chisholm BB, Lew D, Sadasivan K. The use of tobramycin-impregnated polymethylmethacrylate beads in the treatment of osteomyelitis of the mandible: report of three cases. J Oral Maxillofac Surg. 1993;51(4):444-449; discussion 449-450.

47. Lewis G, Brooks JL, Courtney HS, Li Y, Haggard WO. An Approach for determining antibiotic loading for a physician-directed antibioticloaded PMMA bone cement formulation. Clin Orthop Relat Res. 2010;468(8):2092-2100.

48. McLaren AC, McLaren SG, Smeltzer M. Xylitol and glycine fillers increase permeability of PMMA to enhance elution of daptomycin. Clin Orthop Relat Res. 2006;451:25-28.

49. Lewis G, Janna S. Estimation of the optimum loading of an antibiotic powder in an acrylic bone cement: gentamicin sulfate in SmartSet HV. Acta Orthop. 2006;77(4):622-627.

50. Mohanty SP, Kumar MN, Murthy NS. Use of antibiotic-loaded polymethyl methacrylate beads in the management of musculoskeletal sepsis - a retrospective study. J Orthop Surg (Hong Kong). 2003;11(1): 73-79.

51. Neut D, van de Belt H, Stokroos I, van Horn JR, van der Mei HC, Busscher HJ. Biomaterial-associated infection of gentamicin-loaded PMMA beads in orthopaedic revision surgery. JAntimicrob Chemother. 2001;47(6):885-891.

52. Sener M, Kazimoglu C, Karapinar H, Günal I, Afşar I, Karataş Sener AG. Comparison of various surgical methods in the treatment of implantrelated infection. Int Orthop. 2010;34(3):419-423.

53. van de Belt H, Neut D, Schenk W, van Horn JR, van Der Mei HC, Busscher HJ. Staphylococcus aureus biofilm formation on different gentamicin-loaded polymethylmethacrylate bone cements. Biomaterials. 2001;22(12):1607-1611.

54. Gazdag AR, Lane JM, Glaser D, Forster RA. Alternatives to autogenous bone graft: efficacy and indications. J Am Acad Orthop Surg. 1995;3(1): $1-8$.

55. Rueger JM. [Bone substitutes. State of the art and: what lies ahead?]. Unfallchirurg. 1996;99(3):228-236. German.

56. iData Research. US Orthopedic Biomaterials Market - 2013 [webpage on the Internet]. iData Research Inc.; 2013. Available from: http://www. idataresearch.com/us-orthopedic-biomaterials-market-research-report2013/.

57. Thomas DB, Brooks DE, Bice TG, DeJong ES, Lonergan KT, Wenke JC. Tobramycin-impregnated calcium sulfate prevents infection in contaminated wounds. Clin Orthop Relat Res. 2005;441:366-371.

58. Dacquet V, Varlet A, Tandogan RN, et al. Antibiotic-impregnated plaster of Paris beads. Trials with teicoplanin. Clin Orthop Relat Res. 1992;282:241-249.
59. Moore WR, Graves SE, Bain GI. Synthetic bone graft substitutes. ANZ J Surg. 2001;71(6):354-361.

60. Kelly CM, Wilkins RM, Gitelis S, Hartjen C, Watson JT, Kim PT. The use of a surgical grade calcium sulfate as a bone graft substitute: result of a multicenter trial. Clin Orthop Relat Res. 2001;382:44-50.

61. Coetzee AS. Regeneration of bone in the presence of calcium sulfate. Arch Otolaryngol. 1980;106(7):405-409.

62. Mirzayan R, Panossian V, Avedian R, Forrester DM, Menendez LR. The use of calcium sulfate in the treatment of benign bone lesions. A preliminary report. J Bone Joint Surg Am. 2001;83-A(3):355-358.

63. Turner TM, Urban RM, Hall DJ, Chye PC, Segreti J, Gitelis S. Local and systemic levels of tobramycin delivered from calcium sulfate bone graft substitute pellets. Clin Orthop Relat Res. 2005;437:97-104.

64. Richelsoph KC, Webb ND, Haggard WO. Elution behavior of daptomycin-loaded calcium sulfate pellets: a preliminary study. Clin Orthop Relat Res. 2007;461:68-73.

65. Webb ND, McCanless JD, Courtney HS, Bumgardner JD, Haggard WO. Daptomycin eluted from calcium sulfate appears effective against Staphylococcus. Clin Orthop Relat Res. 2008;466(6):1383-1387.

66. Dash AK, Suryanarayanan R. An implantable dosage form for the treatment of bone infections. Pharm Res. 1992;9(8):993-1002.

67. McLaren AC. Alternative materials to acrylic bone cement for delivery of depot antibiotics in orthopaedic infections. Clin Orthop Relat Res. 2004;427:101-106.

68. Rutledge B, Huyette D, Day D, Anglen J. Treatment of osteomyelitis with local antibiotics delivered via bioabsorbable polymer. Clin Orthop Relat Res. 2003;411:280-287.

69. Mader JT, Calhoun J, Cobos J. In vitro evaluation of antibiotic diffusion from antibiotic-impregnated biodegradable beads and polymethylmethacrylate beads. Antimicrob Agents Chemother. 1997;41(2): 415-418.

70. Liu SJ, Wen-Neng Ueng S, Lin SS, Chan EC. In vivo release of vancomycin from biodegradable beads. J Biomed Mater Res. 2002;63(6): 807-813.

71. Ueng SW, Yuan LJ, Lin SS, et al. In vitro and in vivo analysis of a biodegradable poly(lactide-co-glycolide) copolymer capsule and collagen composite system for antibiotics and bone cells delivery. J Trauma. 2011;70(6):1503-1509.

72. Ueng SW, Yuan LJ, Lee N, et al. In vivo study of hot compressing molded 50:50 poly (DL-lactide-co-glycolide) antibiotic beads in rabbits. J Orthop Res. 2002;20(4):654-661.

73. Giannoudis PV, Dinopoulos H, Tsiridis E. Bone substitutes: an update. Injury. 2005;36(Suppl 3):S20-S27.

74. Huang ZM, He CL, Yang A, et al. Encapsulating drugs in biodegradable ultrafine fibers through co-axial electrospinning. J Biomed Mater Res A. 2006;77(1):169-179.

75. Göpferich A. Mechanisms of polymer degradation and erosion. Biomaterials. 1996;17(2):103-114.

76. Hench LL, Wilson J. Surface-active biomaterials. Science. 1984; 226(4675):630-636.

77. Lindfors NC, Hyvönen P, Nyyssönen M, et al. Bioactive glass $\mathrm{S} 53 \mathrm{P} 4$ as bone graft substitute in treatment of osteomyelitis. Bone. 2010;47(2):212-218.

78. Hench LL, Paschall HA. Direct chemical bond of bioactive glass-ceramic materials to bone and muscle. J Biomed Mater Res. 1973;7(3):25-42.

79. Drago L, Romanò D, De Vecchi E, et al. Bioactive glass BAG-S53P4 for the adjunctive treatment of chronic osteomyelitis of the long bones: an in vitro and prospective clinical study. BMC Infect Dis. 2013;13:584.

80. McAndrew J, Efrimescu C, Sheehan E, Niall D. Through the looking glass; bioactive glass S53P4 (BonAlive ${ }^{\sqrt{\mathbb{R}}}$ ) in the treatment of chronic osteomyelitis. Ir J Med Sci. 2013;182(3):509-511.

81. Xing J, Hou T, Luobu B, et al. Anti-infection tissue engineering construct treating osteomyelitis in rabbit tibia. Tissue Eng Part A. 2013;19(1-2):255-263.

82. Chang Z, Hou T, Wu X, et al. An anti-infection tissue-engineered construct delivering vancomycin: its evaluation in a goat model of femur defect. Int J Med Sci. 2013;10(12):1761-1770. 
83. Shirtliff ME, Calhoun JH, Mader JT. Experimental osteomyelitis treatment with antibiotic-impregnated hydroxyapatite. Clin Orthop Relat Res. 2002;401:239-247.

84. Rauschmann MA, Wichelhaus TA, Stirnal V, et al. Nanocrystalline hydroxyapatite and calcium sulphate as biodegradable composite carrier material for local delivery of antibiotics in bone infections. Biomaterials. 2005;26(15):2677-2684.

85. Wang Y, Wang X, Li H, et al. Assessing the character of the rhBMP2- and vancomycin-loaded calcium sulphate composites in vitro and in vivo. Arch Orthop Trauma Surg. 2011;131(7):991-1001.

86. Karr JC, Lauretta J, Keriazes G. In vitro antimicrobial activity of calcium sulfate and hydroxyapatite (Cerament Bone Void Filler) discs using heat-sensitive and non-heat-sensitive antibiotics against methicillinresistant Staphylococcus aureus and Pseudomonas aeruginosa. J Am Podiatr Med Assoc. 2011;101(2):146-152.

87. Clinical and Laboratory Standards Institute. Performance Standards for Antimicrobial Susceptibility Testing; Seventeenth Informational Supplement. CLSI document M100-S17 (ISBN 1-56238-625-5). Clinical and Laboratory Standards Institute, Wayne, Pennsylvania 19087-1898. USA, 2007.
88. Karr JC. Management in the wound-care center outpatient setting of a diabetic patient with forefoot osteomyelitis using Cerament Bone Void Filler impregnated with vancomycin: off-label use. J Am Podiatr Med Assoc. 2011;101(3):259-264.

89. Maier GS, Roth KE, Andereya S, et al. In vitro elution characteristics of gentamicin and vancomycin from synthetic bone graft substitutes. Open Orthop J. 2013;7:624-629.

90. Swieringa AJ, Tulp NJ. Toxic serum gentamicin levels after the use of gentamicin-loaded sponges in infected total hip arthroplasty. Acta Orthop. 2005;76(1):75-77.

91. Urban RM, Turner TM, Hall DJ, Infanger S, Cheema N, Lim TH. Healing of large defects treated with calcium sulfate pellets containing demineralized bone matrix particles. Orthopedics. 2003;26(Suppl 5):s581-s585.

92. Holtom PD, Patzakis MJ. Newer methods of antimicrobial delivery for bone and joint infections. Instr Course Lect. 2003;52:745-749.
Orthopedic Research and Reviews

\section{Publish your work in this journal}

Orthopedic Research and Reviews is an international, peer-reviewed, open access journal focusing on the patho-physiology of the musculoskeletal system, trauma, surgery and other corrective interventions to restore mobility and function. Advances in new technologies, materials, techniques and pharmacological agents are particularly welcome. The journal welcomes

\section{Dovepress}

original research, clinical studies, reviews \& evaluations, expert opinion and commentary, case reports and extended reports. The manuscript management system is completely online and includes a very quick and fair peer-review system, which is all easy to use. Visit http://www.dovepress. com/testimonials.php to read real quotes from published authors.

Submit your manuscript here: http://www.dovepress.com/orthopedic-research-and-reviews-journal 